TITLE:

\title{
Gas- and solid/liquid-phase reactions during pyrolysis of softwood and hardwood lignins
}

$\operatorname{AUTHOR}(S):$

Asmadi, Mohd; Kawamoto, Haruo; Saka, Shiro

\section{CITATION:}

Asmadi, Mohd ... [et al]. Gas- and solid/liquid-phase reactions during pyrolysis of softwood and hardwood lignins. Journal of Analytical and Applied Pyrolysis 2011, 92(2): 417-425

\section{ISSUE DATE:}

2011-11

URL:

http://hdl.handle.net/2433/150113

\section{RIGHT:}

(C) 2011 Elsevier B.V.; This is not the published version. Please cite only the published version.; この論文は出版社版でありません。引用の際に は出版社版をご確認ご利用ください。 
2 Gas- and solid/liquid-phase reactions during pyrolysis of softwood and

\section{3 hardwood lignins}

4

5 Mohd Asmadi ${ }^{1}$, Haruo Kawamoto ${ }^{1 *}$, Shiro Saka ${ }^{1}$

6

$7 \quad{ }^{1}$ Graduate School of Energy Science, Kyoto University

8 Yoshida-honmachi, Sakyo-ku, Kyoto 606-8501, Japan

9

$10 *$ Corresponding author: Haruo Kawamoto

11 Graduate School of Energy Science, Kyoto University

12 Yoshida-honmachi, Sakyo-ku, Kyoto 606-8501, Japan

13 Tel/Fax: +81-75-753-4737

14 E-mail: kawamoto@energy.kyoto-u.ac.jp 


\section{Abstract:}

16 Pyrolytic reactions of Japanese cedar (Cryptomeria japonica, a softwood) and Japanese 17 beech (Fagus crenata, a hardwood) milled wood lignins (MWLs) were studied with 18 thermogravimetry (TG) and by pyrolysis in a closed ampoule reactor $\left(\mathrm{N}_{2} / 600{ }^{\circ} \mathrm{C}\right)$. The data were compared with those of guaiacol/syringol as simple lignin model aromatic nuclei. Several DTG peaks were observed around 300-350, 450, 590 and $650{ }^{\circ} \mathrm{C}$. The first DTG peak temperature $\left(326{ }^{\circ} \mathrm{C}\right)$ of beech was lower than that $\left(353{ }^{\circ} \mathrm{C}\right)$ of cedar. This indicates that the volatile formation from cedar MWL is slightly delayed in heating at $600{ }^{\circ} \mathrm{C}$. The gas-phase reactions via GC/MS-detectable low MW products were explainable with the temperature-dependent reactions observed for guaiacol/syringol in our previous paper. The methoxyl groups became reactive at $\sim 450{ }^{\circ} \mathrm{C}$, giving $\mathrm{O}-\mathrm{CH}_{3}$ homolysis products (catechols/pyrogallols) and $\mathrm{OCH}_{3}$ rearrangement products (cresols/xylenols). The former homolysis products were effectively converted into gaseous products (mainly $\mathrm{CO}$ ) at $>550-600{ }^{\circ} \mathrm{C}$. However, the GC/MS-detectable tar yields, especially syringyl unit-characteristic products, were much lower than those from guaiacol/syringol. Thus, contributions of higher MW intermediates and solid/liquidphase reactions are more important in lignin pyrolysis. From the results of stepwise pyrolysis of char+coke fractions at 450 and $600{ }^{\circ} \mathrm{C}$, the methoxyl group-related reactions $\left(450{ }^{\circ} \mathrm{C}\right)$ and intermediates gasification $\left(600{ }^{\circ} \mathrm{C}\right)$ were suggested to occur also in the solid/liquid phase. This was consistent with the DTG peaks observed around these temperatures. These solid/liquid-phase reactions reduced the tar formation, especially

Keywords:

44 Lignin; Pyrolysis; Reactions; Gas phase; Solid/liquid phase; Softwood; Hardwood 


\section{Introduction}

Lignin is an aromatic polymer consisting of phenylpropane-units linked through etherand condensed-types of linkages. The aromatic ring structures are different depending on the wood species; softwood lignins have 4-hydroxy-3-methoxyphenyl (guaiacyl) type with small amount of $p$-hydroxyphenyl type, while hardwood lignins contain 3,5-dimethoxy-4hydroxyphenyl (syringyl) type as well as the guaiacyl type. Accordingly, such difference in the aromatic ring structure is expected to affect the pyrolysis behaviors of softwood and hardwood lignins.

Initial pyrolytic reactions of lignin have been studied extensively by thermogravimetry and NMR analysis and with model compounds. Major initial weight loss is observed in the temperature range $300-400{ }^{\circ} \mathrm{C}$ in TG analysis [1-7]. Devolatilization tends to be more effective in hardwood lignins [1,3,5,7], which was explained by the smaller contents of the condensed (C-C) types of interphenylpropane-linkages, arising from the inclusion of the syringyl type. How and Schultz [8] reported the cleavage of the $\beta$-ether linkage, the most abundant structure in lignin, at a temperature as low as $220{ }^{\circ} \mathrm{C}$ based on the CP/MAS NMR data. Model compound studies [9-15] suggest the pathways and molecular mechanisms for cleavage of the ether linkages, including homolysis/heterolysis and role of quinine methide intermediate. The model compound data were also used for the study of depolymerization behavior of isolated lignins [14]. Chemical structures of the primary volatile products have been studied mainly using gas chromatography (GC) coupled with mass spectrometry (MS) [16-21]. Various monoaromatic compounds with guaiacyl or syringyl moiety have been identified, which have various double bond side-chains such as $>\mathrm{C}=\mathrm{C}<,-\mathrm{CHO}$ and $>\mathrm{C}=\mathrm{O}$ at positions para to the phenolic hydroxyl groups.

These primary products are further pyrolyzed in gas and solid/liquid phases (secondary reactions). Hosoya et al. [22] compared the primary pyrolysis and some secondary reactions behaviors of softwood lignin and other carbohydrate constituents (cellulose and hemicelluloses) with an open-top reactor at $800{ }^{\circ} \mathrm{C}$. They found that gas-phase carbonization (coking) was significant for lignin, although coking from cellulose- and hemicelluloses-derived tars was observed only after condensing on the reactor wall with lower temperature. They also found that methoxyl group was a key structure for these coking reactions of lignin and proposed an o-quinonemethide as an intermediate [23].

The gas-phase conversions of lignin-derived tars were studied with a closed ampoule reactor at $600{ }^{\circ} \mathrm{C}$ [24]. Major structural changes occur in side-chain and aromatic ring substitution pattern: side-chain structures were changed from unsaturated to saturated types, and this was explained with the condensation of the double bond structures followed by cracking; aromatic ring substitution pattern was also changed simultaneously from guaiacol $\left(\mathrm{OCH}_{3}\right)$ type to catechol $(\mathrm{OH})$ and cresol $\left(\mathrm{CH}_{3}\right)$ types. Hosoya et al. [25] reported that these pyrolysis reactions were very much influenced by the carbohydrate-derived vapors acting as a H-donor. Gas formation behaviors were also compared between tar and char fractions from cellulose and lignin [26]. However, these results are only for guaiacyl lignins, and further conversion pathways from the catechol/cresol intermediates have not been studied. 
Unlike the guaiacyl lignins, there are few papers relating to the pyrolytic reactions of syringyl and hardwood lignins. Asmadi et al. [27] compared the pyrolysis behaviors of Japanese cedar (Cryptomeria japonica, a softwood) and Japanese beech (Fagus crenata, a hardwood) wood samples. As for lignin-related products, coke formation was observed more extensively for beech wood; although syringol (2,6-dimethoxyphenol) derivatives with various double bond side-chains were obtained as well as the corresponding guaiacol (2methoxyphenol) types in GC/MS-analysis, the compositions became similar for the two species after a long heating time.

The secondary reactions pathways of guaiacols and syringols have been studied with simple model compounds such as guaiacol [23,28-34] and syringol [28,35,36]. Two types of reactions relating to the methoxyl group occur at $>450{ }^{\circ} \mathrm{C}$, namely $\mathrm{O}-\mathrm{CH}_{3}$ homolysis and radical-induced $\mathrm{OCH}_{3}$ rearrangement (ipso-substitution) to convert methoxyl to methyl groups. Catechols/pyrogallols and cresols/xylenols are the products formed through these respective pathways, together with $\mathrm{CH}_{4}$ formation. A large amount of coke (defined as a carbonaceous substance via volatiles) is also formed at this stage [23,28]. Asmadi et al. [28] compared these resactions between guaiacol and syringol in an ampoule reactor $\left(\mathrm{N}_{2} / 600^{\circ} \mathrm{C}\right)$. Syringol gave more coke and $\mathrm{CH}_{4}$ than guaiacol, and this was explained with the additional methoxyl group in syringol.

Asmadi et al. [37] also compared the pyrolytic reactivities of the catechols/pyrogallols

106

107 and cresols/xylenols types intermediates in a closed ampoule reactor $\left(\mathrm{N}_{2} / 600{ }^{\circ} \mathrm{C}\right)$. They found that the reactivity increased with an increase in the number of substituent groups, and the accelerating effect was greater for $\mathrm{OH}$ than for $\mathrm{CH}_{3}$. Accordingly, catechols/pyrogallols were effectively converted into gaseous products, mainly $\mathrm{CO}$, at $>550-600{ }^{\circ} \mathrm{C}$, while cresols/xylenols were converted much more slowly into demethylation products together with $\mathrm{H}_{2}, \mathrm{CH}_{4}$ and coke. The syringol-derived intermediates with more substituents group were generally more reactive than the corresponding guaiacol-derived intermediates.

Thus, information on the pyrolytic reactions of guaiacol and syringol is available. With these knowledges, it is possible to compare the pyrolysis behaviors of softwood and hardwood lignins. In the present work, pyrolytic reactions of milled wood lignins (MWLs) isolated from Japanese cedar (Cryptomeria japonica, a softwood) and Japanese beech (Fagus crenata, a hardwood) were studied at the molecular level, focusing on the gas- and solid/liquid-phase reactions.

\section{Experimental}

\subsection{Materials}

MWLs were isolated from Japanese cedar and Japanese beech wood samples according to the reported procedure [38]. Guaiacol, syringol and other chemicals were mainly purchased from Nacalai Tesque Inc. (Kyoto, Japan), as guaranteed grades. The syringyl/guaiacyl $(\mathrm{S} / \mathrm{G})$ ratio of the beech $\mathrm{MWL}$ was evaluated as 2.3 from the syringaldehyde/vanillin (S/V) ratio obtained by alkaline nitrobenzene oxidation. 


\subsection{Methods}

The TG analysis was conducted with a Shimadzu TGA 50 instrument (Shimadzu, Kyoto, Japan). Sample $(1 \mathrm{mg})$ was heated in a platinum cell at $10{ }^{\circ} \mathrm{C} / \mathrm{min}$ under nitrogen flow $(10 \mathrm{~mL} / \mathrm{min})$. Two types of reactors were used in this study, namely an open-top and a closed ampoule reactor. The open-top reactor was used to study the initial devolatilization step, since the volatile (tar) products are cooled by condensing on the upper side of the reactor wall. Secondary reactions of the volatile products were expected to occur in the closed ampoule reactor.

\subsubsection{Pyrolysis in a closed ampoule reactor}

MWL $(10 \mathrm{mg})$ was placed at the bottom of a Pyrex glass ampoule (internal diameter $8.0 \mathrm{~mm}$, length $120 \mathrm{~mm}$, wall thickness $1.0 \mathrm{~mm}$ ). The glass ampoule was closed after exchanging the inside air with $\mathrm{N}_{2}$ using an aspirator. The ampoule was heated for $40-600 \mathrm{~s}$ in an upright position, in a muffle furnace preheated to $600{ }^{\circ} \mathrm{C}$, through a small hole at the top of the furnace. It took about 120 s that the inside temperature was raised to the set temperature $\left(600{ }^{\circ} \mathrm{C}\right)$. After pyrolysis, the ampoule was immediately cooled by flowing air for $1 \mathrm{~min}$, and the non-condensable gases were recovered according to our previously paper [26]. A glass tube with a septum rubber stopper was attached to the top of the ampoule through a silicon tube. The air inside the resulting closed space was exchanged with argon by using a vacuum pump and a gas tight syringe filled with argon, the syringe was replaced by an empty syringe, and then the top of the ampoule was broken to release the gaseous products into the closed space. The non-condensable gases were analyzed by gas chromatography (GC) as described later. After the collection of the gaseous products, the ampoule was rinsed with $\mathrm{MeOH}(2 \times 1.0 \mathrm{~mL})$ to obtain $\mathrm{MeOH}-$ soluble and insoluble (char+coke) fractions. The latter fraction, adhering to the ampoule, was dried in an oven $\left(105^{\circ} \mathrm{C}\right)$ for $24 \mathrm{~h}$, and the char+coke yield was determined from the weight difference of the ampoule after incineration of char+coke in air at $600{ }^{\circ} \mathrm{C}$ for $2 \mathrm{~h}$. The $\mathrm{MeOH}$-soluble tar yield was obtained by subtracting the amounts of char+coke and non-condensable gases.

\subsubsection{Pyrolysis in an open-top reactor}

Similar pyrolysis experiments were conducted with an open-top reactor, which consisted of a glass tube reactor $(10 \mathrm{~mm}$ in diameter and $300 \mathrm{~mm}$ long) attached to a nitrogen bag. MWL (10 mg) was placed at the bottom of the tube reactor, and about two thirds of the reactor from the bottom was heated for $180 \mathrm{~s}$ by inserting it into a muffle furnace preheated at $400{ }^{\circ} \mathrm{C}$, through a small hole at the top of the furnace. After pyrolysis, the reactor was removed from the furnace and cooled by flowing air for $1 \mathrm{~min}$. The non-condensable gases were analyzed by GC, and the tar and char+coke fractions were obtained by a procedure similar to that described above.

\subsubsection{Stepwise pyrolysis of char+coke fractions}


The MWLs and their char+coke fractions were pyrolyzed stepwise in the closed ampoule reactor. MWL was first pyrolyzed at $350{ }^{\circ} \mathrm{C}$ for $300 \mathrm{~s}$ in a manner similar to that described above. The resulting char+coke fraction after tar extraction with $\mathrm{MeOH}$ was washed with distilled water, then oven dried at $105{ }^{\circ} \mathrm{C}$ for $24 \mathrm{~h}$. The ampoule with char+coke fraction was closed again after exchanging the inside air with $\mathrm{N}_{2}$ using an aspirator, and heated at $450{ }^{\circ} \mathrm{C}$ for $300 \mathrm{~s}$. After tar extraction and drying, the resulting char+coke fraction obtained at $450{ }^{\circ} \mathrm{C}$ was heated further at $600{ }^{\circ} \mathrm{C}$ for $300 \mathrm{~s}$.

\subsection{Product analysis}

Non-condensable gases were determined with Micro GC using a Varian CP-4900 chromatograph under the following conditions: channel 1) column: MS5A $10 \mathrm{~m}$; carrier gas: argon; column temperature: $100{ }^{\circ} \mathrm{C}$; column pressure: $170 \mathrm{kPa}$; thermal conductivity detector (TCD); retention times (s): $\mathrm{H}_{2}(26.4), \mathrm{N}_{2}(45.7), \mathrm{O}_{2}(35.4), \mathrm{CH}_{4}(60.6)$ and $\mathrm{CO}$ (86.9); channel 2) column: PoraPLOT Q $10 \mathrm{~m}$; carrier gas: helium; column temperature: $80{ }^{\circ} \mathrm{C}$ : column pressure: $190 \mathrm{kPa}$; TCD detector; retention time (s): $\mathrm{CO}_{2}$ (19.9).

Low molecular weight (MW) products in the $\mathrm{MeOH}$-soluble fractions were determined by GC-MS analysis. Identification of the products was achieved by comparing retention times and mass fragmentation patterns with those of authentic compounds or literature data according to our previous papers [22,24,27]. Quantification was made from the relative peak area against $p$-dibromobenzene as an internal standard by using the response factors obtained for the authentic compounds. GC/MS analysis was carried out using a Hitachi G-7000 gas chromatograph and Hitachi M9000 mass spectrometer under the following conditions: column: Shimadzu CBP-M25-O25 (length $25 \mathrm{~m}$, diameter $0.25 \mathrm{~mm})$; injector temperature: $250{ }^{\circ} \mathrm{C}$; column temperature: $40{ }^{\circ} \mathrm{C}(1$ $\mathrm{min}), 40 \rightarrow 300{ }^{\circ} \mathrm{C}(1 \rightarrow 53 \mathrm{~min}), 300{ }^{\circ} \mathrm{C}(53 \rightarrow 60 \mathrm{~min})$; carrier gas: helium; flow rate: $1.5 \mathrm{~mL} / \mathrm{min}$; emission current: $15 \mu \mathrm{A}$; ionization time: $100 \mathrm{~ms}$.

Gel permeation chromatography (GPC) was carried out with a Shimadzu LC-10A instrument under the following conditions; column: Shodex KF $801+\mathrm{KF}$ 802+KF 802.5+KF 803; flow rate: $0.6 \mathrm{~mL} / \mathrm{min}$; eluent: THF; detector: $\mathrm{UV}_{254} \mathrm{~nm}$; temperature: $40{ }^{\circ} \mathrm{C}$; retention times (min): guaiacol (64.6), syringol (65.2), pyrocatechol (63.9), 3methylcatechol (63.6), 4-methylcatechol (63.5), pyrogallol (62.2), 5-methylpyrogallol (61.7), phenol (66.0), 2-ethylphenol (64.6), o-cresol (65.5), p-cresol (65.2), 2,3-xylenol (65.2), 2,4-xylenol (64.9), 2,6-xylenol (65.2), 2,3-benzofuran (70.3), biphenyl (68.7), xanthene (69.7), naphthalene (71.2), 2-methylnaphthalene (70.2), 1-methylnaphthalene (71.0), phenanthrene (70.5) and anthracene (70.3).

All experiments were repeated at least three times, and the product yields were not very different in these sets of experiments, although the data presented in this paper were not treated statistically. We also confirmed that the relationships between the yields and pyrolysis time or other pyrolysis parameters were not different in these experiments. 


\section{Results and discussion}

\subsection{Thermogravimetry and pyrolysis in an open-top reactor}

The TG and DTG curves of beech and cedar MWLs are depicted in Fig. 1. Weight reduction started at temperatures slightly higher than $200{ }^{\circ} \mathrm{C}$, and the major initial weight loss was observed between 200 and $400{ }^{\circ} \mathrm{C}$. The DTG peak temperature $\left(326{ }^{\circ} \mathrm{C}\right)$ of beech MWL was lower than that $\left(353^{\circ} \mathrm{C}\right)$ of cedar MWL, thus the pyrolytic devolatilization of beech MWL occurred at a lower temperature than that of cedar. NMR analysis [8] and model compound studies [9-15] suggest that the ether linkages between phenylpropane units are cleaved in this temperature range. However, there are no papers comparing the reactivities of pyrolytic cleavage of the ether linkages between guaiacyl and syringyl lignins. Further study will be necessary to address the reason for such difference in the DTG peak temperature.

After the initial weight loss around $300-400{ }^{\circ} \mathrm{C}$, cedar MWL gave larger amount of residues than beech MWL, and the weight differences were almost constant (7 8\%) for these two MWLs in the temperature range $400-800{ }^{\circ} \mathrm{C}$. Thus, such difference would arise from the difference in the initial devolatilization step. More efficient devolatilization of hardwoods have been reported [1,3,5,7], and this is explained by the lower contents of the condensed types of linkages in hardwood lignins, which are resistant to pyrolytic depolymerization.

Several DTG peaks were also observed at higher temperatures, namely $~ 450$, $\sim 590$ and $\sim 650{ }^{\circ} \mathrm{C}$. Accordingly, some pyrolytic devolatilization occurs at these temperatures. This is discussed later with the results of stepwise pyrolysis of char+coke fractions from MWLs.

To confirm the TG results, the MWLs were pyrolyzed in an open-top reactor under $\mathrm{N}_{2}$ at $400{ }^{\circ} \mathrm{C}$, which was slightly higher than the lowest DTG peak temperatures and lower than the temperature range $\left(\sim 450{ }^{\circ} \mathrm{C}\right)$ reported for the $\mathrm{O}-\mathrm{CH}_{3}$ bond homolysis and rearrangement reactions occurring [28]. Furthermore, the volatile products were expected to be stabilized by condensing on the reactor wall at lower temperatures. Accordingly, these pyrolysis conditions were thought to be suitable for investigating the initial devolatilization process. As expected, the yields of volatile products (tar and gas) were much higher for beech than for cedar $\left(\mathrm{N}_{2} / 400{ }^{\circ} \mathrm{C} / 180 \mathrm{~s}\right)$. Tar $(45.3 \mathrm{wt} \%)$ and gas (5.6 wt $\%$ ) yields from beech MWL were almost double those (tar $23.5 \mathrm{wt} \%$, gas 3.8 wt $\%$ ) from cedar MWL.

\subsection{Pyrolysis in a closed ampoule reactor}

In the closed ampoule reactor, secondary reactions of the primary volatile products are more prevalent, to form secondary products including coke and gas. Fig. 2 shows photographs of the reactors and $\mathrm{MeOH}$-soluble fractions obtained by pyrolysis of cedar and beech MWLs under $\mathrm{N}_{2}$ at $600{ }^{\circ} \mathrm{C}$ for $40-600 \mathrm{~s}$ in the closed ampoule reactor, and subsequent tar extraction with $\mathrm{MeOH}$. Time-course changes of the $\mathrm{MeOH}$-insoluble (char+coke), MeOH-soluble (tar) and gas yields are also included. 
Two kinds of carbonaceous substances were observed at the bottom and upper side of the reactor wall. In this paper, "char" is defined as the insoluble substances observed at the bottom of the ampoule where MWL was placed. On the other hand, "coke" is defined as the insoluble substances stuck on the upper side of the reactor wall, since the term "coke" is usually used for the carbonaceous substances formed via low MW volatile intermediates. Char+coke yields tended to be lower in beech MWL than in cedar. This may arise from the more efficient devolatilization of beech MWL in the primary devolatilization step.

As reported previously [28,37], coke formation from guaiacol/syringol as model aromatic nuclei occurred in two stages (1st stage: 80-120 s, 2nd stage: 120-600 s). Since the 1st stage coking is related to the reactions of the methoxyl groups, syringol with additional methoxyl group was much more effective than guaiacol. The 2 nd stage coking involved the coking reactions of volatile products, such as catechols, pyrogallols, cresols and xylenols, and guaiacol was more effective in this 2 nd stage coking. Although the differences for the MWLs were smaller than those observed for guaiacol/syringol, the beech MWL (syringol/guaiacyl ratio: 2.3/1) tended to produce more 1st stage coke, while the 2nd stage coking was rather more noticeable for cedar MWL (mostly guaiacyl units) (pictures in Fig. 2).

A noticeable difference was observed for the tar yields up to $120 \mathrm{~s}$. The tar yield from beech MWL gradually decreased with increasing pyrolysis time, whereas the tar yield from cedar MWL had a maximum at $80 \mathrm{~s}$. Such difference is consistent with the lower devolatilization temperature of beech MWL (Fig. 1). Beech MWL may produce volatile products earlier than cedar during heating up process, since it was required about $120 \mathrm{~s}$ for inside temperature of the ampoule to reach the set temperature $600{ }^{\circ} \mathrm{C}$. This may be related to the color change of the $\mathrm{MeOH}$-soluble fractions. Color of the $\mathrm{MeOH}-$ soluble fractions became brown in the early stage of pyrolysis $(<80 \mathrm{~s})$, and became increasingly discolored with increasing pyrolysis time. This coloration and discoloration behavior was slightly delayed in cedar MWL.

According to our previous paper [28], syringol gave more gas, especially $\mathrm{CH}_{4}$ and $\mathrm{CO}_{2}$, than guaiacol under similar conditions. However, the gas yields were very similar for cedar and beech MWLs. The yields of each gaseous component are shown in Fig. 3, together with those from guaiacol and syringol. Although the yields were different between MWLs and guaiacol/syringol, the formation behaviors of these gaseous products were similar. Inside temperature of the ampoule was raised with increasing pyrolysis time: $459^{\circ} \mathrm{C}(40 \mathrm{~s}), 569{ }^{\circ} \mathrm{C}(80 \mathrm{~s})$ and $590{ }^{\circ} \mathrm{C}(120 \mathrm{~s})$. Formation of $\mathrm{CO}_{2}$ started from 40 $\mathrm{s}$ where formation of other gaseous products was not effective. This indicates that $\mathrm{CO}_{2}$ is formed at lower pyrolysis temperature. Major $\mathrm{CO}_{2}, \mathrm{CH}_{4}$ and $\mathrm{CO}$ formation was observed during heating up conditions (80 120 s). Based on the reactivities of the intermediates from guaiacol/syringol in our previous paper [37], the $\mathrm{O}-\mathrm{CH}_{3}$ bond homolysis is a source of $\mathrm{CH}_{4}\left(400-450{ }^{\circ} \mathrm{C}\right)$, and decomposition of catechol/pyrogallol type intermediates gives large amounts of $\mathrm{CO}\left(>550 \sim 600{ }^{\circ} \mathrm{C}\right)$. The $\mathrm{H}_{2}$ formation was slightly delayed and 
continued even after $120 \mathrm{~s}$. This can be explained by the earlier proposal that the charring, coking and PAH formation reactions generate hydrogen radicals [37]. Demethylation of methylated phenols such as cresols and xylenols through substitution by hydrogen is suggested as a source of $\mathrm{CH}_{4}$ in the period 120-600 s [37].

The GC/MS-detectable low MW tar components in MeOH-soluble fractions changed drastically with pyrolysis time. The total-ion chromatograms at $40 \mathrm{~s}$ (maximum temperature: $459{ }^{\circ} \mathrm{C}$ ) are shown in Fig. 4. These products were not compared quantitatively, since some of the authentic compounds were not available for obtaining their response factors in GC/MS analysis. Most of the products (40 s) from cedar and beech MWLs were guaiacols and guaiacols/syringols, respectively, with various substituents at the $p$-position of the phenolic hydroxyl groups. The side-chains included saturated, unsaturated, aldehyde and ketone types, and these compositions were not greatly different from the results obtained with the open-top reactor $\left(\mathrm{N}_{2} / 400{ }^{\circ} \mathrm{C} / 180 \mathrm{~s}\right)$. Thus, the GC/MS-detectable tars at $40 \mathrm{~s}$ were the primary volatile products from the MWLs.

By increasing the pyrolysis time to $80 \mathrm{~s}$ (maximum temperature: $569^{\circ} \mathrm{C}$ ), these initial products disappeared almost completely, and catechols/pyrogallols and cresols/xylenols became the major components, which are formed through $\mathrm{O}-\mathrm{CH}_{3}$ bond homolysis and rearrangement reactions, respectively [28]. Fig. 5 shows the time-course changes of the yields of these products, which were quantified with the authentic compounds. Formation and decomposition behaviors of these products are explainable with those of guaiacol/syringol reported previously [28,37], except for their yields described later. Some 4-methyl derivatives (4-methylcatechol, $p$-cresol and 2,4-xylenol) tended to have higher relative concentrations in MWL than in guaiacol/syringol. These products may arise from the side-chains of lignin phenylpropane-units. Short-lived catechols/pyrogallols 1-6 $\left(\mathrm{O}-\mathrm{CH}_{3}\right.$ bond homolysis products) are explained with their higher decomposition reactivities to form $\mathrm{CO}$ and $\mathrm{CO}_{2}$ (in the case of pyrogallols) [37], and this is consistent with the $\mathrm{CO}$ and $\mathrm{CO}_{2}$ formation in Fig. 3. As for cresols/xylenols 8$11\left(\mathrm{OCH}_{3}\right.$ rearrangement products), demethylation of xylnols and cresols is reported to occur more slowly at 120-600 s, giving cresols, phenols, $\mathrm{CH}_{4}, \mathrm{H}_{2}$ and coke [37]. Formation of PAHs was observed only at longer pyrolysis times $>120 \mathrm{~s}$.

Fig. 6 shows the yields of GC/MS-detectable tars, compared with those from guaiacol/syringol [28]. The yields from the MWLs were much lower than those from guaiacol/syringol. In particular, the syringyl unit-characteristic products were almost negligible for beech MWL. Accordingly, most of the GC/MS-detectable tars from beech MWL became guaiacyl unit-characteristic products (at 80-600 s), and their yields were lower than those from cedar MWL. These results are consistent with our earlier observation for Japanese cedar and Japanese beech wood samples under similar conditions [27].

\subsection{Stepwise pyrolysis of residues (char+coke)}


According to the model compound studies [10,11,14], various guaiacol/syringol derivatives with double bond side-chains are formed from lignin, including coniferyl alcohol and stilbene from the $\beta$-ether and $\beta$-aryl types of model dimers, respectively. These initial products may condense [39]. The three-dimensional structures of lignin also prevent the formation of monoaromatic products. These processes may increase the contribution of solid/liquid-phase pyrolysis for MWLs. As already described, the TG analysis (Fig. 1) showed the DTG peaks at $\sim 450$ and $\sim 590{ }^{\circ} \mathrm{C}$, which are in accordance with the temperatures at which the $\mathrm{O}-\mathrm{CH}_{3}$ bond homolysis/rearrangement reactions and gasification of catechol/pyrogallol type intermediates, respectively, are reported to start in the gas phase $[28,37]$. These considerations suggest that similar reactions also occur in the solid/liquid phase.

To confirm that hypothesis, cedar and beech MWLs or their char+coke fractions were pyrolyzed stepwise $\left(350 \rightarrow 450 \rightarrow 600{ }^{\circ} \mathrm{C}\right)$. First, the MWLs were pyrolyzed in the ampoule reactor at $350{ }^{\circ} \mathrm{C}$ for $300 \mathrm{~s}$ (Step 1), where the methoxyl groups are stable. After tar extraction with $\mathrm{MeOH}$ and subsequent drying, the char+coke fractions $(\mathrm{MeOH}-$ insoluble fractions) were pyrolyzed again at $450{ }^{\circ} \mathrm{C}$ for $300 \mathrm{~s}$ (Step 2), where the methoxyl groups become reactive. The resulting char+coke fractions were further pyrolyzed at $600{ }^{\circ} \mathrm{C}$ for $300 \mathrm{~s}$ (Step 3). The formation behaviors of gas, tar and char+coke in each step are shown in Fig. 8, along with the photographs of the reactors after tar extraction.

Although coke (insoluble substances observed around the upper side of the reactor wall) was not observed in Step $1\left(350{ }^{\circ} \mathrm{C}\right)$, coke was clearly observed in Step 2 $\left(450{ }^{\circ} \mathrm{C}\right)$, where the methoxyl groups are reactive. This is consistent with the earlier proposal that reactions of the methoxyl groups are important in coke formation [23]. The amounts (not quantified) in Step $2\left(450{ }^{\circ} \mathrm{C}\right)$ were not so different from those of Step 3 $\left(600{ }^{\circ} \mathrm{C}\right)$. Thus, coke precursors were formed from the char fractions $\left(350{ }^{\circ} \mathrm{C}\right)$ at $450{ }^{\circ} \mathrm{C}$. At this temperature, $o$-cresol, 2,4-xylenol and 2,6-xylenol, which are the products of the $\mathrm{OCH}_{3}$ rearrangement, were detected, although these yields were not large. As for the gaseous products, $\mathrm{CH}_{4}$, which would form from the $\mathrm{O}-\mathrm{CH}_{3}$ bond homolysis followed by $\mathrm{H}$-abstraction, was produced more selectively in Step $2\left(450{ }^{\circ} \mathrm{C}\right)$. Catechols/pyrogallols were not observed in GC/MS analysis, which are also the products from the homolysis pathway. These structures may be included in higher MW products.

At $600{ }^{\circ} \mathrm{C}$ (Step 3), the major products from the char+coke fractions $\left(450{ }^{\circ} \mathrm{C}\right.$ ) were gaseous products. Although the yields can not be compared directly, total gas yields (15.0 and $16.6 \mathrm{wt} \%$, based on MWL) from these three steps of pyrolysis correspond to 50.0 and $56.1 \%$ of those from the MWLs $\left(600^{\circ} \mathrm{C} / 600\right.$ s, Fig. 2), respectively. These results suggest that contribution of solid/liquid-phase reactions in gas formation is not small in MWL. Formation of large amounts of CO in Step $3\left(600{ }^{\circ} \mathrm{C}\right)$ is explainable with the decomposition of catechol/pyrogallol type structures [37]. Jakab et al. [2] reported the 
of methane formation through the $\mathrm{O}-\mathrm{CH}_{3}$ bond homolysis [28] and demethylation of cresols/xylenols [37], respectively.

These lines of evidence confirm that reactions that were found to occur in the gas phase also proceeded in the solid/liquid phase. The methoxyl group-related reactions (O$\mathrm{CH}_{3}$ bond homolysis and $\mathrm{OCH}_{3}$ rearrangement) occurred at $450{ }^{\circ} \mathrm{C}$ in the solid/liquid phase to form gaseous products (especially $\mathrm{CH}_{4}$ ), coke and smaller amounts of GC/MSdetectable cresols/xylenols. No GC/MS-detectable catechols/pyrogallols were obtained. At a higher temperature of $600{ }^{\circ} \mathrm{C}$, gasification of the intermeditate structures in the solid/liquid phase may become effective.

\subsection{GPC analysis of tar fractions}

Fig. 7 illustrates some GPC data of $\mathrm{MeOH}$-soluble tar fractions in pyrolysis (a) and stepwise pyrolysis (b) of the MWLs, compared with those (c) of guaiacol/syringol pyrolysis. In early stage of pyrolysis (40 s), the signals from the MWLs (Fig. 7a) were observed in higher MW regions than those from guaiacol/syringol (Fig. 7c). By comparison with the chromatograms obtained with the open-top reactor, the products in the closed ampoule reactor tended to have higher MWs. This tendency was more noticeable for beech MWL. Condensation of the primary volatile products may be a reason. Nakamura et al. [39] reported that guaiacol derivatives with double bond sidechains, such as coniferyl alcohol and vinyl guaiacol, condensed rapidly even at a lower temperature of $250{ }^{\circ} \mathrm{C}$. Hosoya et al. [24] observed the structural changes of side-chain from unsaturated to saturated types during pyrolysis of cedar MWL at $600{ }^{\circ} \mathrm{C}$ in an ampoule reactor. They explained these structural changes with condensation and subsequent cracking of the resulting condensates. Such condensation reactions, which occurred before the methoxyl groups became reactive, may reduce the yields of GC/MSdetectable low MW products, especially the syringyl unit-characteristic products (Figs. 5 and 6).

With increase in pyrolysis time to $600 \mathrm{~s}$, high MW products disappeared and the shapes of the chromatograms became similar for these MWLs (Fig. 7a) and guaiacol/syringol (Fig. 7c). These chromatograms include two signals corresponding to cresols/xylenols and PAHs. At this stage, the $\mathrm{MeOH}$-soluble fractions became colorless (pictures in Fig. 2).

In stepwise pyrolysis (Fig. 7b), the chromatograms (Step 1, $350{ }^{\circ} \mathrm{C}$ ) are similar to those with the open-top reactor (Fig. 7a). The char fractions obtained in Step $1\left(350{ }^{\circ} \mathrm{C}\right)$ gave tars which are observed in slightly lower MW regions (Step 2, $450{ }^{\circ} \mathrm{C}$ ). Interestingly, the char+coke fractions obtained in Step $2\left(450^{\circ} \mathrm{C}\right)$ gave almost no signals at $600{ }^{\circ} \mathrm{C}$ (Step 3), unlike the formation of large signals around 64 and $69 \mathrm{~min}$ in pyrolysis of MWLs and guaiacol/syringol. Accordingly, formation of tar including PAHs is not important from the char+coke fractions obtained at $450{ }^{\circ} \mathrm{C}$ where the methoxyl groups are reactive. This was also confirmed by GC/MS analysis. PAHs may form in the gas phase probably via the intermediates formed through the $\mathrm{O}-\mathrm{CH}_{3}$ bond homolysis and 
rearrangement pathways. In our previous paper [37], catechols/pyrogallols tended to produce biphenyl, naphthlenes and phenanthrene more selectively, while cresols/xylenols formed xanthenes and anthracene preferentially under similar conditions.

\section{Conclusions}

Fig. 9 illustrates a pyrolysis pathway of lignin in a closed ampoule reactor $\left(\mathrm{N}_{2}\right)$ $600^{\circ} \mathrm{C}$ ), as proposed by the present and literature data. This includes gas- and solid/liquid-phase reactions. Some important reactions are also included; ether cleavage (depolymerization) (300-350 $\left.{ }^{\circ} \mathrm{C}\right)$ [9-15], the methoxyl group-related reactions (400$450{ }^{\circ} \mathrm{C}$ ) [28], and gas and PAH formation from the pyrolysis intermediates (>550$\left.600{ }^{\circ} \mathrm{C}\right)$ [37]. The gas-phase reactions were explainable with the reactions of guaiacol/syringol in our previous papers [28,37]. In lignin pyrolysis, contributions of the gas-phase reactions are comparatively small due to side-chain network in lignin macromolecule. Furthermore, low MW products formed from lignins in early stage, which are guaiacols/syringols with double bond side-chains, are reactive for condensation [24,39]. These reduce the yields of GC/MS-detectable low MW products. Based on the results of stepwise pyrolysis of char+coke fractions at 450 and $600{ }^{\circ} \mathrm{C}$, the $\mathrm{O}-\mathrm{CH}_{3}$ bond homolysis/ rearrangement $\left(450{ }^{\circ} \mathrm{C}\right)$ and intermediates gasification $\left(600{ }^{\circ} \mathrm{C}\right)$, both of which are reported in the gas-phase pyrolysis of guaiacol/syringol [28, 37], were suggested to occur also in the solid/liquid phase. These solid/liquid-phase reactions gave gaseous products, while reduced the yields of GC/MS-detectable low MW tars, especially catechols/pyrogallols and PAHs. Coke precursors and smaller amounts of cresols/xylenols were formed in the solid/liquid phase at $450{ }^{\circ} \mathrm{C}$.

As for the differences for Japanese cedar (a softwood) and Japanese beech (a hardwood) MWLs, the following results were obtained.

1. Japanese beech MWL produced volatile products at lower temperature than cedar. Thus, volatile formation from beech MWL occurred slightly earlier than that from cedar MWL in heating at $600{ }^{\circ} \mathrm{C}$.

2. Japanese beech MWL tended to form more coke at a short pyrolysis time. This is consistent with the higher coking reactivity of syringol than guaiacol in our previous paper [28].

3. Yields of GC/MS-detectable low MW tars were lower in beech than in cedar when the methoxyl groups became reactive $\left(>450{ }^{\circ} \mathrm{C}\right)$. This was due to almost negligible yields of the syringyl unit-characteristic products in beech MWL.

These results would be useful to improve the thermochemical conversion processes such as fast pyrolysis and gasification.

\section{Acknowledgments}


453 This work was supported by a Grant-in-Aid for Scientific Research (B)(2) (No. 454 203801035007, 2008.4-2011.3) and the Kyoto University Global COE program of 455 "Energy Science in the Age of Global Warming". 


\section{References}

[1] O. Faix, E. Jakab, F. Till, T. Székely, Wood Sci. Technol. 22 (1988) 323.

[2] E. Jakab, O. Faix, F. Till, J. Anal. Appl. Pyrol. 40-41 (1997) 171.

[3] J. Li, L. Bin, X. Zhang, Polym. Degrad. Stabil. 78 (2002) 279.

[4] S. Kubo, J.F. Kadla, J. Wood Chem. Technol. 28 (2008) 106.

[5] Q. Liu, S. Wang, Y. Zheng, Z. Luo, K. Cen, J. Anal. Appl. Pyrol. 82 (2008) 170.

[6] S. Wang, K. Wang, Q. Liu, Y. Gu, Z. Luo, K. Cen, T. Fransson, Biotechnol. Adv. 27 (2009) 562.

[7] D.J. Gardner, T.P. Schultz, G.D. McGinnis, J. Wood Chem. Technol. 5 (1985) 85.

[8] J.F. Haw, T.P. Schultz, Holzforschung 39 (1985) 289.

[9] R. Brežný, V. Mihálov, V. Kváčik, Holzforschung 37 (1983) 199.

[10] H. Kawamoto, S. Horigoshi, S. Saka, J. Wood Sci. 53 (2007)168.

[11] H. Kawamoto, S. Horigoshi, S. Saka, J. Wood Sci. 53 (2007)268.

[12] H. Kawamoto, T. Nakamura, S. Saka, Holzforschung 62 (2008) 50.

[13] H. Kawamoto, M. Ryoritani, S. Saka, J. Anal. Appl. Pyrol. 81 (2008) 88.

[14] T. Nakamura, H. Kawamoto, S. Saka, J. Anal. Appl. Pyrol. 81 (2008) 173.

[15] T. Watanabe, H. Kawamoto, S. Saka, Holzforschung, 63 (2009) 424.

[16] C. Saiz-Jimenez, J.W. De Leeuw, Org. Geochem. 10 (1986) 869.

[17] R.J. Evans, T.A. Milne, M.N. Soltys, J. Anal. Appl. Pyrol. 9 (1986) 207.

[18] O. Faix, D. Meier, I. Grobe, J. Anal. Appl. Pyrol. 11 (1987) 403.

[19] W. Genuit, J.J. Boon, O. Faix, Anal. Chem. 59 (1987) 508.

[20] P.F. Greenwood, J.D.H. van Heemst, E.A. Guthrie, P.G. Hatcher, J. Anal. Appl. Pyrol. 62 (2002) 365.

[21] J.R. Obst, J. Wood Chem. Technol. 3 (1983) 377.

[22] T. Hosoya, H. Kawamoto, S. Saka, J. Anal. Appl. Pyrol. 78 (2007) 328.

[23] T. Hosoya, H. Kawamoto, S. Saka, J. Anal. Appl. Pyrol. 84 (2009) 79.

[24] T. Hosoya, H. Kawamoto, S. Saka, J. Anal. Appl. Pyrol. 83 (2008) 78.

[25] T. Hosoya, H. Kawamoto, S. Saka, J. Anal. Appl. Pyrol. 85 (2009) 237.

[26] T. Hosoya, H. Kawamoto, S. Saka, J. Anal. Appl. Pyrol. 83 (2008)71.

[27] M. Asmadi, H. Kawamoto, S. Saka, J. Wood Sci. 56 (2010) 319.

[28] M. Asmadi, H. Kawamoto, S. Saka, J. Anal. Appl. Pyrol., in press (doi:10.1016/j.jaap.2011.04.011).

[29] J.R. Lawson, M.T. Klein, Ind. Eng. Chem. Fundam. 24 (1985) 203.

[30] A.I. Vuori, J.B. Bredenberg, ACS Division of Fuel Chemistry 30 (1985) 366.

[31] A.I. Vuori, Fuel 65 (1986) 1575.

[32] A.I. Vuori, J.B. Bredenberg, Ind. Eng. Chem. Res. 26 (1987) 359.

[33] M.M. Suryan, S.A. Kafafi, S.E. Stein, J. Am. Chem. Soc. 111 (1989) 1423.

[34] E. Dorrestijn, P. Mulder, J. Chem. Soc. 2 (1999) 777.

[35] C.P. Masuku, Holzforschung 45 (1991) 181.

[36] C.H. Vane, G.D. Abbott, Org. Geochem. 30 (1999) 1535. 
497 [37] M. Asmadi, H. Kawamoto, S. Saka, J. Anal. Appl. Pyrol., in press 498 (doi:10.1016/j.jaap.2011.04.012).

499 [38] A. Bjorkman, Svensk Paperstidn. 59 (1956) 477.

500 [39] T. Nakamura, H. Kawamoto, S. Saka, J. Wood Chem. Technol. 27 (2007) 121. 


\section{Figure Legends}

Fig. 1. TG and DTG curves of Japanese beech and Japanese cedar MWLs (heating rate: $10{ }^{\circ} \mathrm{C} / \mathrm{min} ; \mathrm{N}_{2}$ flow rate: $\left.10 \mathrm{~mL} / \mathrm{min}\right)$.

Fig. 2. Photographs of ampoule reactors (after tar extraction) and MeOH-soluble tar fractions, and yields of $\mathrm{MeOH}$-insoluble (char+coke), $\mathrm{MeOH}$-soluble (tar) and gas fractions during pyrolysis of Japanese beech and Japanese cedar MWLs in an ampoule reactor $\left(\mathrm{N}_{2} / 600{ }^{\circ} \mathrm{C} / 40\right.$ $600 \mathrm{~s})$.

Fig. 3. Yields of gaseous products from Japanese beech and Japanese cedar MWLs, compared with those from guaiacol and syringol (ampoule reactor/ $\mathrm{N}_{2} / 600{ }^{\circ} \mathrm{C} / 40-600 \mathrm{~s}$ ). ${ }^{\mathrm{a}}$ Ref. [28].

Fig. 4. Total-ion chromatograms in GC/MS-analysis of the MeOH-soluble fractions obtained from pyrolysis of Japanese beech and Japanese cedar MWLs in a closed ampoule reactor $\left(600{ }^{\circ} \mathrm{C} / 40\right.$ s). G: 4-hydroxy-3-methoxyphenyl, S: 3,5-dimethoxy-4-hydroxyphenyl.

Fig. 5. Yields of GC/MS-detectable tar components during pyrolysis of Japanese beech and Japanese cedar MWLs in a closed ampoule reactor $\left(\mathrm{N}_{2} / 600{ }^{\circ} \mathrm{C} / 40-600 \mathrm{~s}\right)$.

Fig. 6. Changes in the GC/MS-detectable tar yields during pyrolysis of Japanese beech and Japanese cedar MWLs, compared with those of guaiacol and syringol (closed ampoule reactor $\left./ \mathrm{N}_{2} / 600{ }^{\circ} \mathrm{C}\right) .{ }^{\text {a }}$ Guaiacyl unit-characteristic products: 1-3 and 7-10, ${ }^{\mathrm{b}}$ syringyl unitcharacteristic products: 4-6 and 11, ${ }^{\mathrm{c}}$ PAHs: 12-18, ${ }^{\mathrm{d}}$ Ref. [28].

Fig. 7. Formation behaviors of gas, tar and coke in stepwise pyrolysis of Japanese cedar and Japanese beech MWLs and their char+coke fractions (MeOH-insoluble residues) in an 
ampoule reactor. Pictures: reactors after pyrolysis and subsequent tar extraction with $\mathrm{MeOH}$, ${ }^{\mathrm{a}} \mathrm{MWL} / \mathrm{N}_{2} / 350{ }^{\circ} \mathrm{C} / 300 \mathrm{~s},{ }^{\mathrm{b}}$ Residue from Step $1\left(350{ }^{\circ} \mathrm{C}\right) / \mathrm{N}_{2} / 450{ }^{\circ} \mathrm{C} / 300 \mathrm{~s},{ }^{\mathrm{c}}$ Residue from Step $2\left(450{ }^{\circ} \mathrm{C}\right) / \mathrm{N}_{2} / 600{ }^{\circ} \mathrm{C} / 300 \mathrm{~s}$.

Fig. 8. GPC chromatograms of MeOH-soluble tar fractions (detector $\mathrm{UV}_{254 \mathrm{~nm}}$ ) obtained from pyrolysis (a) and stepwise pyrolysis (b) of Japanese beech and Japanese cedar MWLs, as compared with those (c) of guaiacol and syringol of our previous data (Ref. [28]). Pyrolysis conditions of MWLs and guaiacol/syringol: closed ampoule/ $\mathrm{N}_{2} / 600{ }^{\circ} \mathrm{C}$, stepwise pyrolysis conditions: see footnote of Fig. 7, (I) catechols and pyrogallols (compounds: 1-6); (II) cresols and xylenols (compounds: 7-11): (III) benzofuran, xanthene and PAHs (compounds: 12-18).

Fig. 9. A proposed gas- and solid/liquid-phase pyrolysis pathway of lignin in a closed ampoule reactor under $\mathrm{N}_{2}$ at $600{ }^{\circ} \mathrm{C}$. 


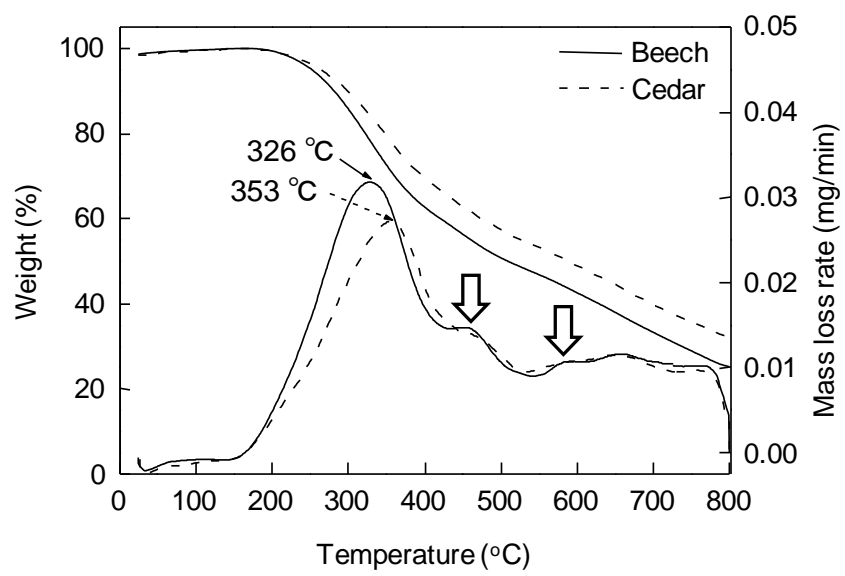

Fig. 1. TG and DTG curves of Japanese beech and Japanese cedar MWLs (heating rate: $10{ }^{\circ} \mathrm{C} / \mathrm{min} ; \mathrm{N}_{2}$ flow rate: 10 $\mathrm{mL} / \mathrm{min}$ ). 
Beech

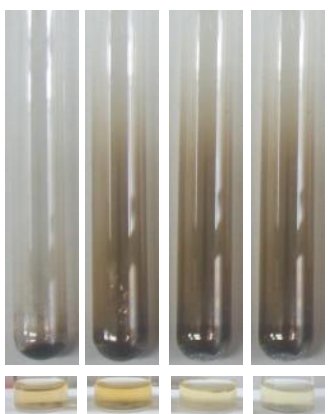

40s 80 s 120s 600s
Cedar

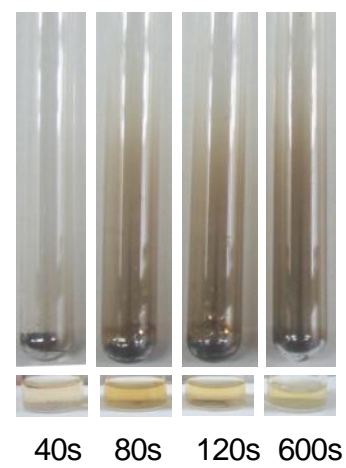

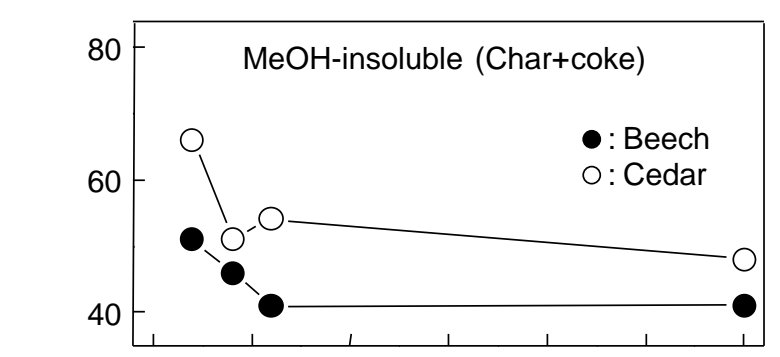
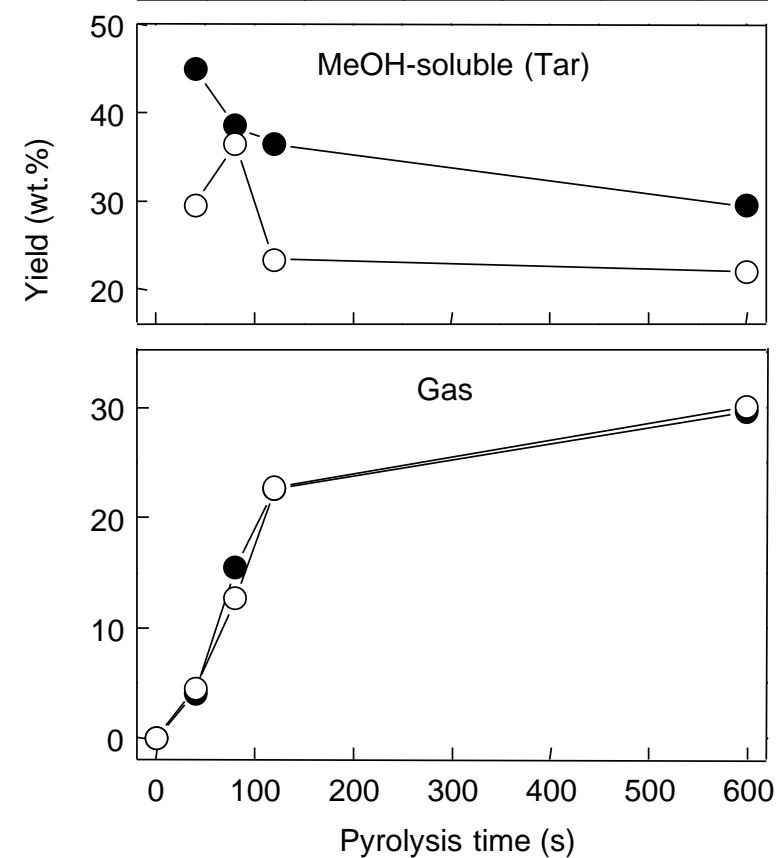

Fig. 2. Photographs of ampoule reactors (after tar extraction) and $\mathrm{MeOH}$-soluble tar fractions, and yields of $\mathrm{MeOH}$-insoluble (char+coke), $\mathrm{MeOH}$-soluble (tar) and gas fractions during pyrolysis of Japanese beech and Japanese cedar MWLs in an ampoule reactor $\left(\mathrm{N}_{2} / 600^{\circ} \mathrm{C} / 40-600 \mathrm{~s}\right)$. 


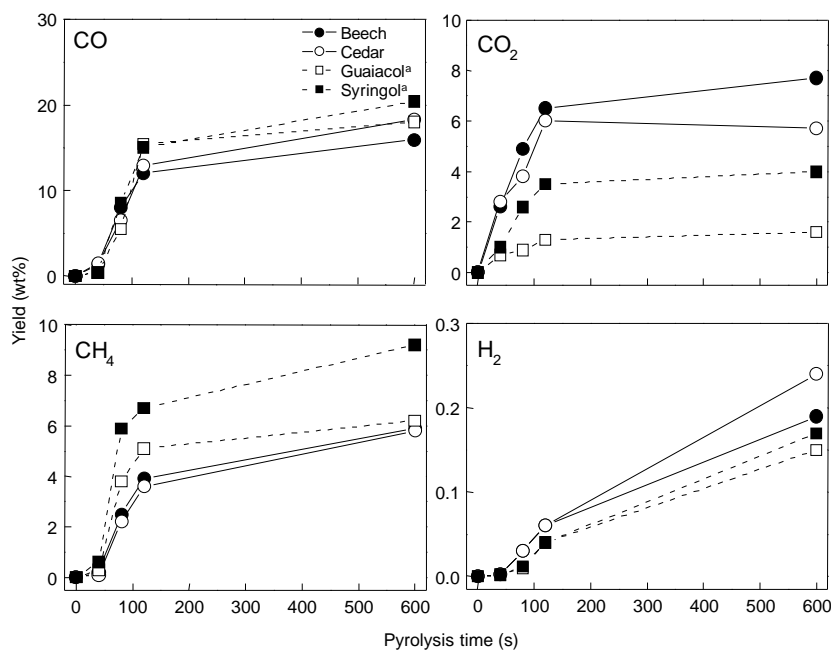

Fig. 3. Yields of gaseous products from Japanese beech and Japanese cedar MWLs, compared with those from guaiacol and syringol (ampoule reactor $/ \mathrm{N}_{2} / 600{ }^{\circ} \mathrm{C} / 40-600 \mathrm{~s}$ ). ${ }^{a}$ Ref. [28]. 


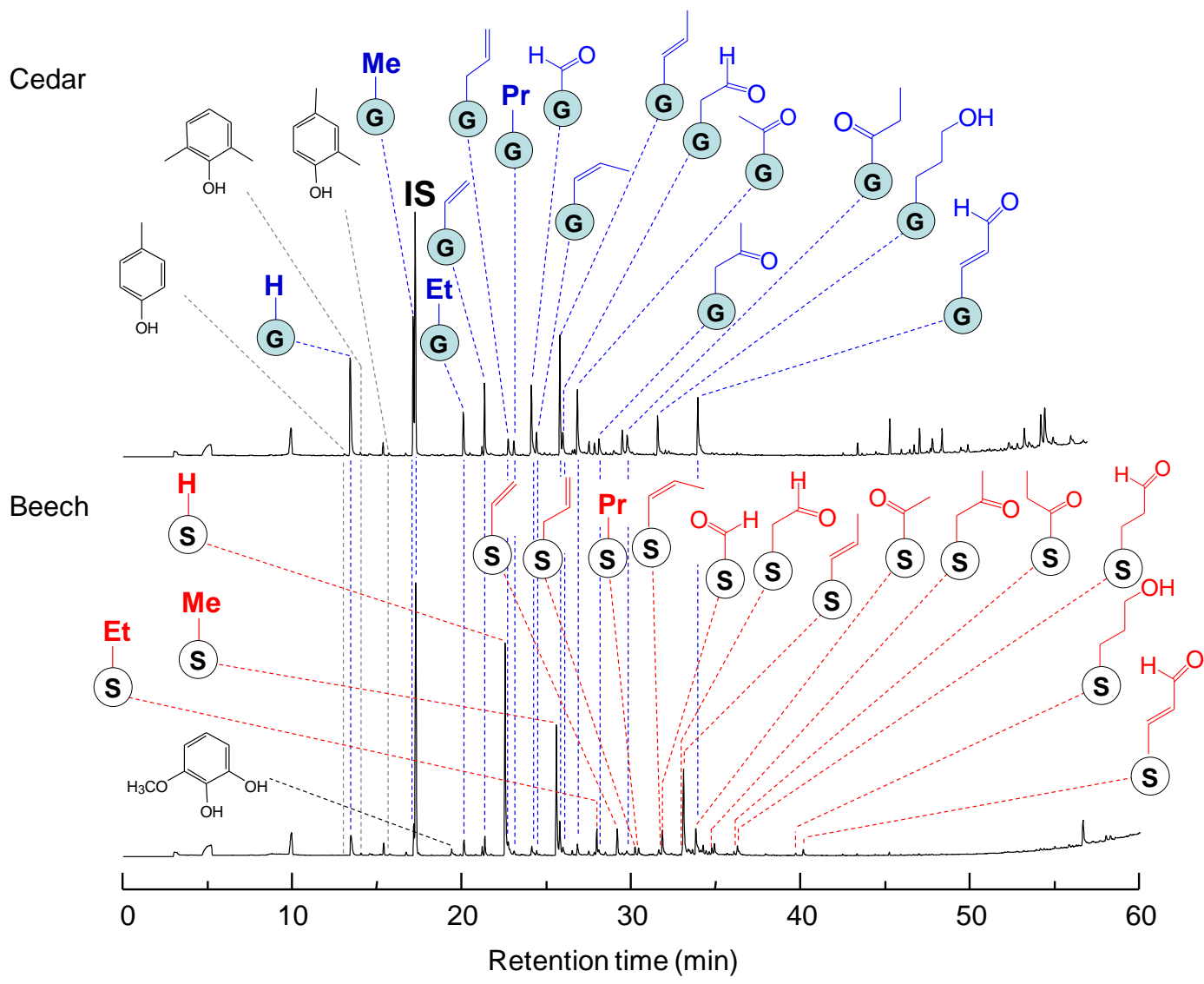

Fig. 4. Total-ion chromatograms in GC/MS-analysis of the MeOH-soluble fractions obtained from pyrolysis of Japanese beech and Japanese cedar MWLs in a closed ampoule reactor $\left(600{ }^{\circ} \mathrm{C} / 40 \mathrm{~s}\right)$. G: 4hydroxy-3-methoxyphenyl, S: 3,5-dimethoxy-4-hydroxyphenyl. 

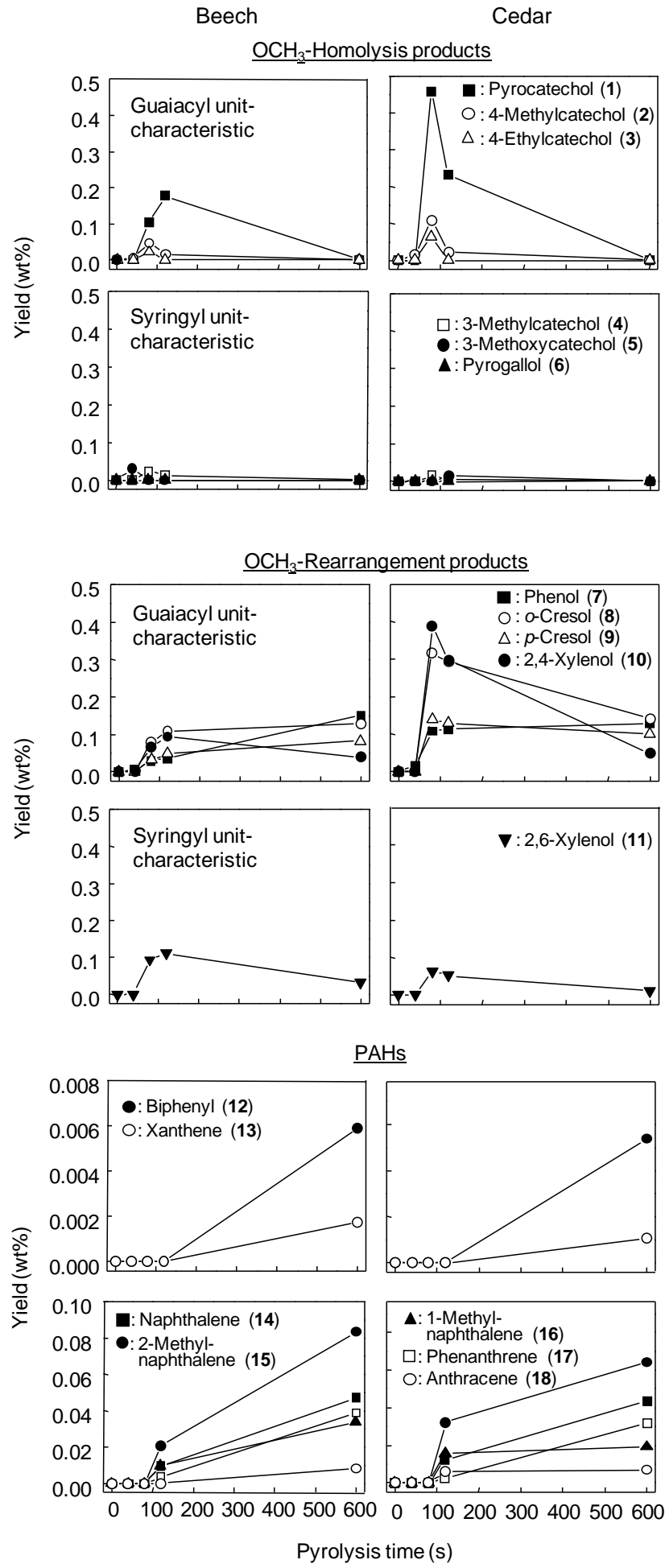

Fig. 5. Yields of GC/MS-detectable tar components during pyrolysis of Japanese beech and Japanese cedar MWLs in a closed ampoule reactor $\left(\mathrm{N}_{2} / 600{ }^{\circ} \mathrm{C} / 40-600 \mathrm{~s}\right)$. 


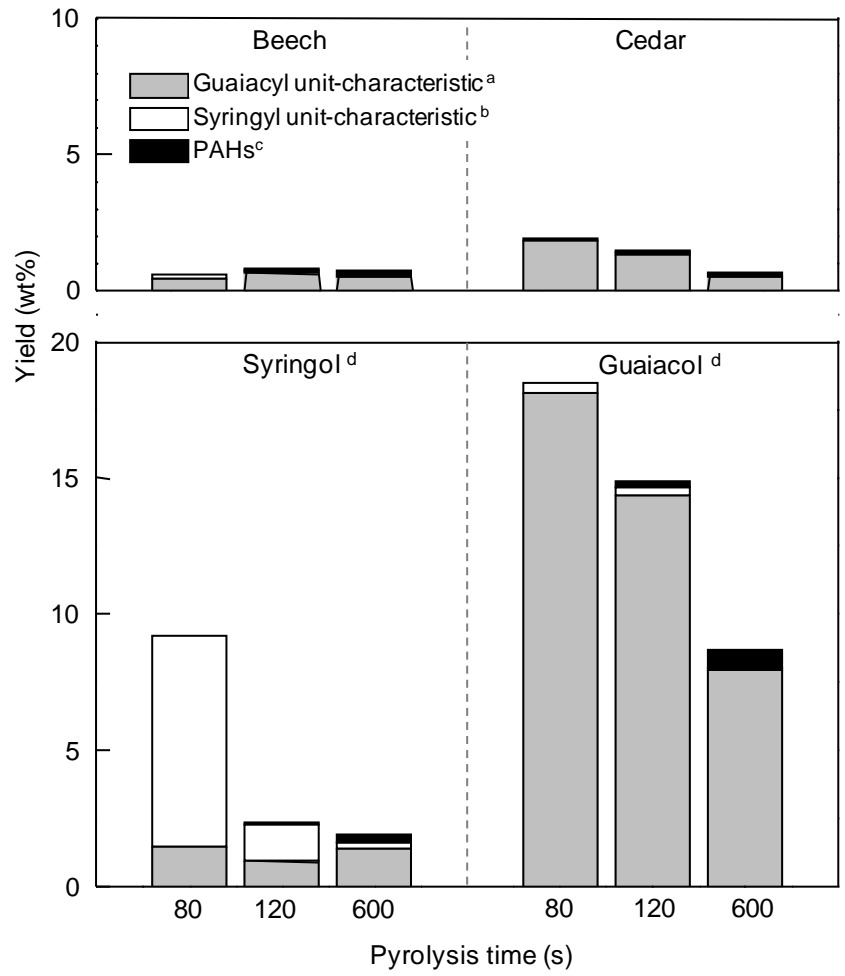

Fig. 6. Changes in the GC/MS-detectable tar yields during pyrolysis of Japanese beech and Japanese cedar MWLs, compared with those of guaiacol and syringol (closed ampoule reactor $/ \mathrm{N}_{2} / 600{ }^{\circ} \mathrm{C}$ ). ${ }^{\text {a }}$ Guaiacyl unit-characteristic products: $1-3$ and 7-10, ${ }^{b}$ syringyl unit-characteristic products: 4-6 and 11, ${ }^{\mathrm{c}}$ PAHs: 12-18, ${ }^{\mathrm{d}}$ Ref. [28]. 

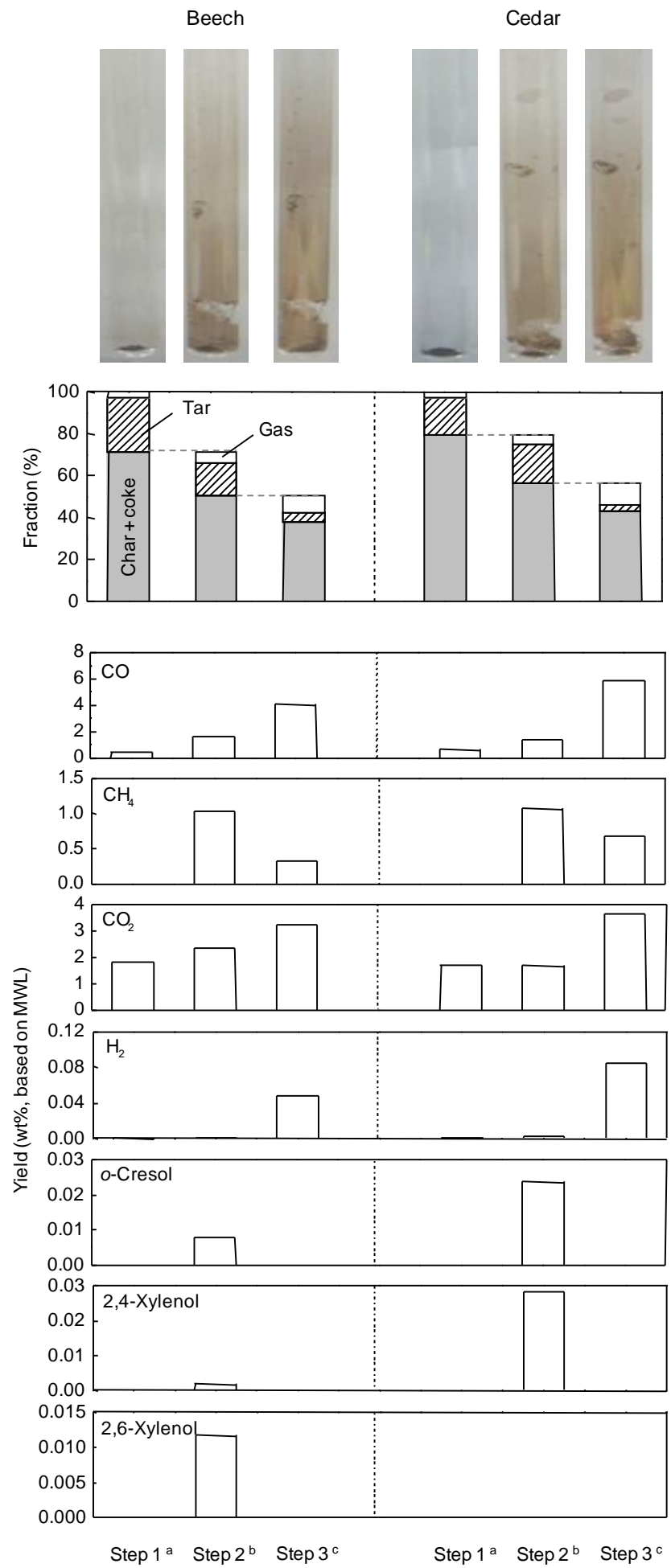

Fig. 7. Formation behaviors of gas, tar and coke in stepwise pyrolysis of Japanese cedar and Japanese beech MWLs and their char+coke fractions ( $\mathrm{MeOH}$-insoluble residues) in an ampoule reactor. Pictures: reactors after pyrolysis and subsequent tar extraction with $\mathrm{MeOH}$,

a $\mathrm{MWL} / \mathrm{N}_{2} / 350{ }^{\circ} \mathrm{C} / 300 \mathrm{~s}$, b Residue from Step 1 $\left(350{ }^{\circ} \mathrm{C}\right) / \mathrm{N}_{2} / 450{ }^{\circ} \mathrm{C} / 300 \mathrm{~s},{ }^{\mathrm{c}}$ Residue from Step 2 $\left(450{ }^{\circ} \mathrm{C}\right) / \mathrm{N}_{2} / 600{ }^{\circ} \mathrm{C} / 300 \mathrm{~s}$. 


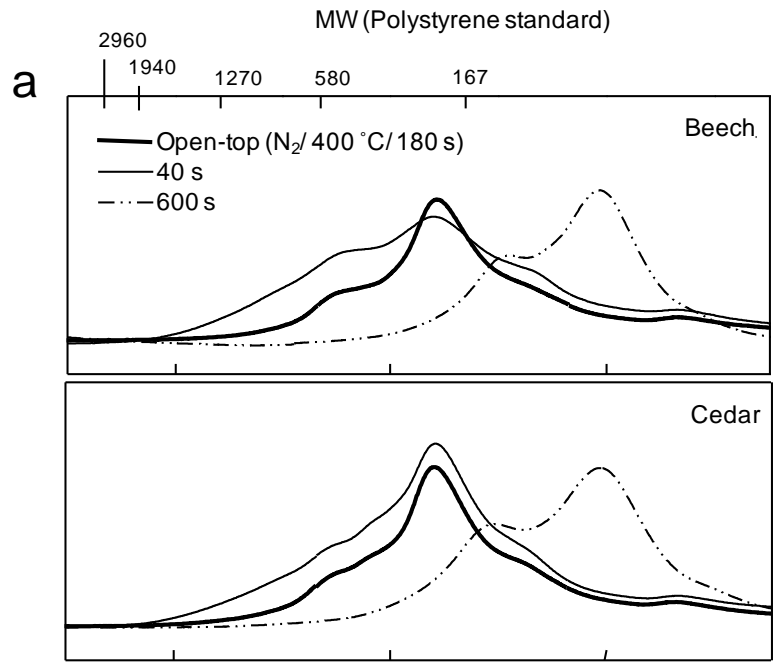

b

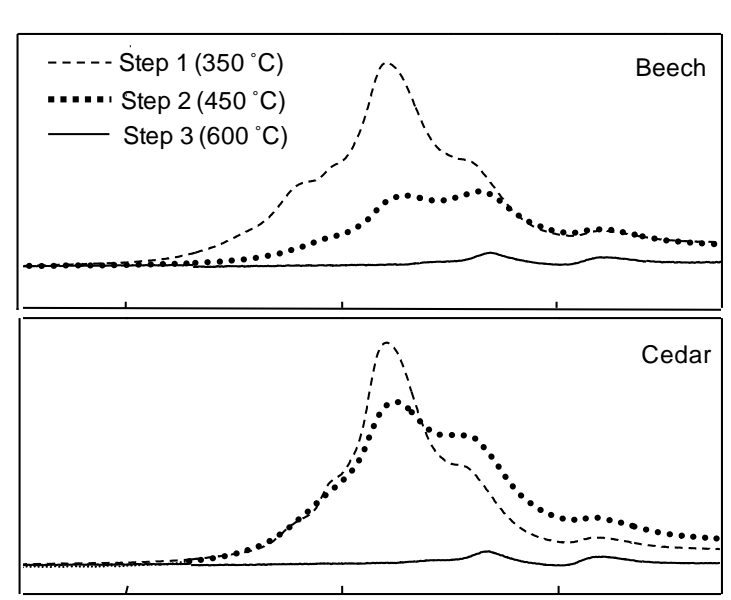

C

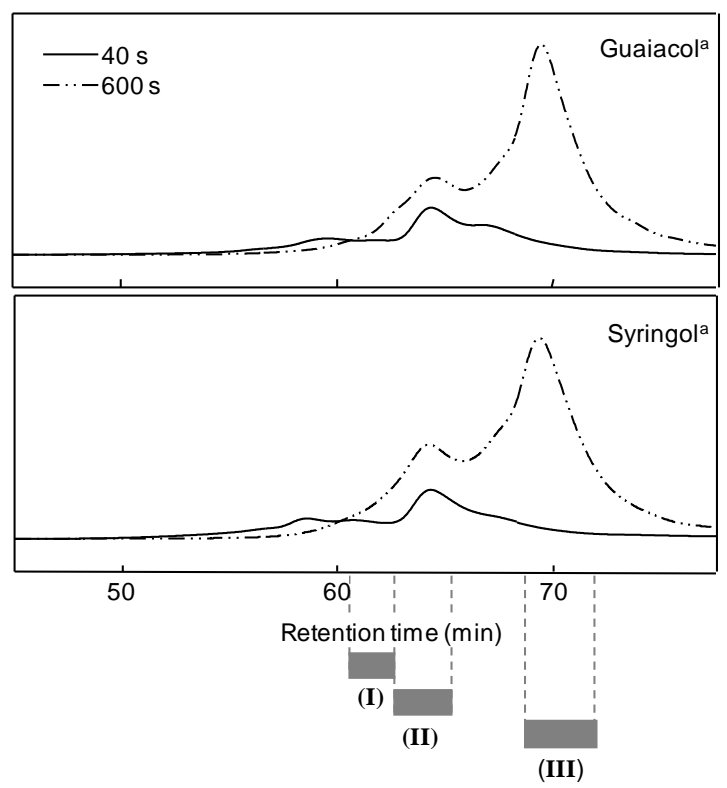

Fig. 8. GPC chromatograms of $\mathrm{MeOH}$-soluble tar fractions (detector $\mathrm{UV}_{254 \mathrm{~mm}}$ ) obtained from pyrolysis (a) and stepwise pyrolysis (b) of Japanese beech and Japanese cedar MWLs, as compared with those (c) of guaiacol and syringol of our previous data (Ref. [28]). Pyrolysis conditions of MWLs and guaiacol/syringol: closed ampoule $/ \mathrm{N}_{2} / 600{ }^{\circ} \mathrm{C}$, stepwise pyrolysis conditions: see footnote of Fig. 7, (I) catechols and pyrogallols (compounds: 1-6); (II) cresols and xylenols (compounds: 7-11): (III) benzofuran, xanthene and PAHs (compounds: 12-18). 


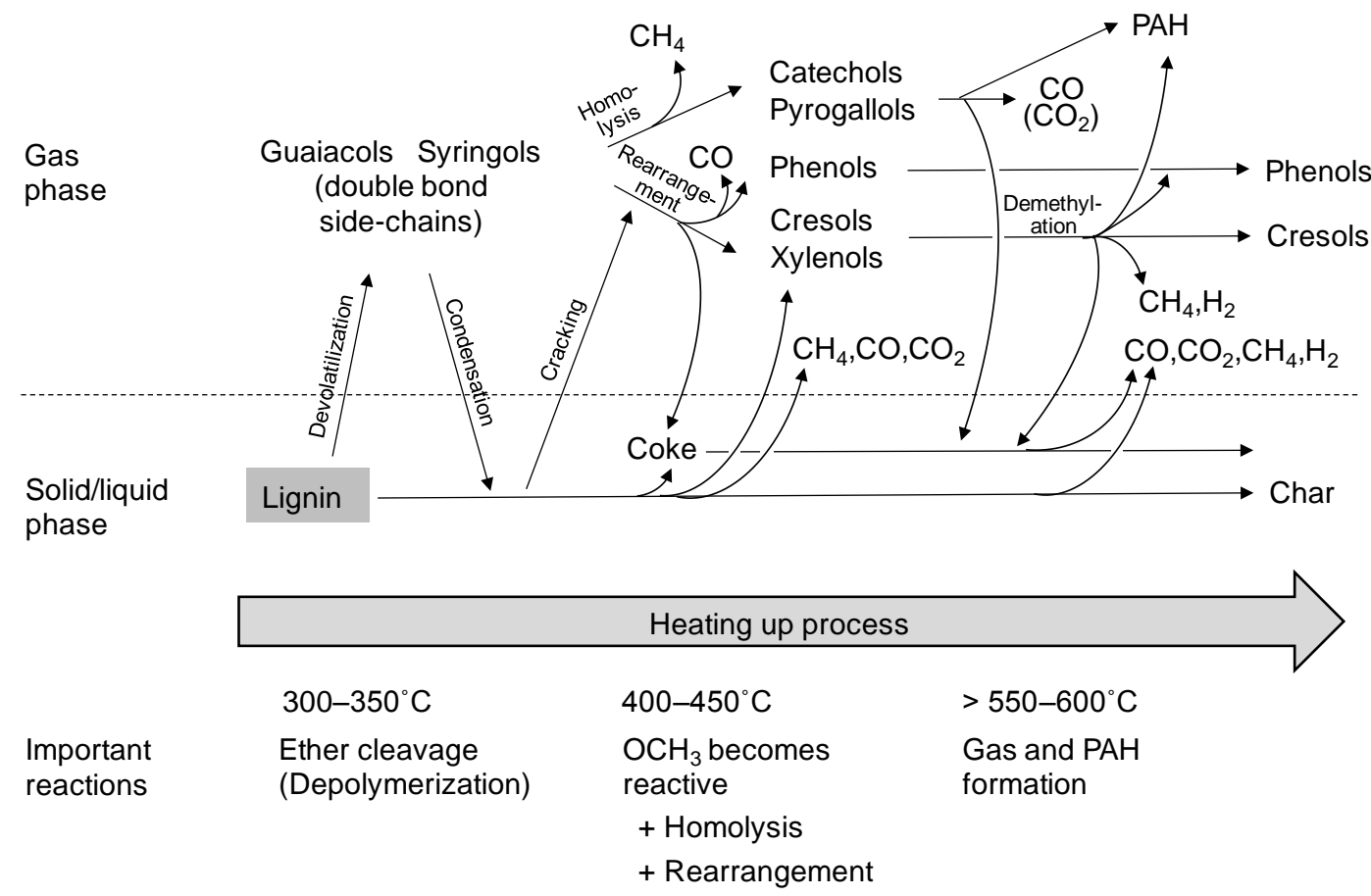

Fig. 9. A proposed gas- and solid/liquid-phase pyrolysis pathway of lignin in a closed ampoule reactor under $\mathrm{N}_{2}$ at $600{ }^{\circ} \mathrm{C}$. 
